\title{
FERREIRO VÁZQUEZ, Óscar. Traducir e interpretar lo públi- co. Granada: Editorial Comares. 2016, 232 p.
}

Xoán Manuel Garrido Vilariño*

Universidade de Vigo

Este volume, editado por Óscar Ferreiro Vázquez, constitui a terceira publicação do Mestrado em Tradução para a Comunicação Internacional no qual se reúnem os contributos dos professores e dos investigadores que também colaboram no programa de doutoramento Tradução \& Paratradução, ambos da Universidade de Vigo. Alguns capítulos têm um carácter exploratório da mediação linguístico-cultural e outros descrevem os fenómenos que afetam a pessoa que traduz e interpreta no espaço público: todos eles procuram conhecer, de forma direta e livre de preconceitos, as normas e as práticas culturais associadas a atos de tradução e interpretação de cada lugar e de cada momento que analisam.

A autora do prólogo, Martha Pulido Correa, anuncia que a identidade da pessoa que traduz e interpreta é um dos núcleos sobre os que assenta esta monografia. Trata-se de una identidade num sentido amplo, enunciada em função não só dos seus pertences, mas também e, sobretudo, da constituição ou formação dos atributos que vai adquirindo ao longo da história, em suma, da identidade profissional de quem traduz e de quem interpreta.

\footnotetext{
* Professor da Universidade de Vigo. Doutor en Tradução e Interpretacão. E-mail: garrido@uvigo.es
} 
A metodologia de análise está descrita no capítulo inicial, a cargo do editor, intitulado «Visiones para traducir lo público en traducción e interpretación», cujos pressupostos teóricos se centram nos níveis empírico, social e discursivo. Estes correspondem aos estabelecidos por L' École de Vigo, assim denominada pelo filósofo da tradução Alexis Nouss e pelo investigador principal do grupo TI4, Tradução \& Paratradução, José Yuste Frías. Estes três níveis de análise estão amplamente aplicados no capítulo intitulado «Paratraducción de la identidad celta en el discurso público de las instituciones gallegas» de Alberto Álvarez Lugrís, no qual se analisa a manipulação dos referentes identitários nos discursos políticos na Galiza. Sobre o mito fundacional do celtismo proposto pelo galeguismo desde o século XIX e pelo nacionalismo galego nos começos do século XX, o autor estuda os elementos textuais e paratextuais tanto verbais como não verbais para expor a estratégia de despolitização deste mito e de desideologização da sociedade levada a cabo pela direita política galega desde 1978. Na realidade, esta estratégia tem a sua origem no franquismo, imediatamente depois da Guerra Civil, momento em que se aproveita de um galeguismo cultural desarmado voluntariamente no político, ao que se permite uma certa liberdade de ação, mas só no terreno intelectual; já na democracia, as sucessivas presidências da Xunta de Galicia desenvolveram a manobra absorvendo os setores conservadores do galeguismo e apropriando-se do discurso e da figura dos nacionalistas históricos.

A emergência do intérprete funcionário público nos primeiros anos da colónia na América hispânica está documentada na segunda contribuição de Óscar Ferreiro Vázquez, cujo título é «Las ordenanzas sobre interpretación del virrey Francisco Álvarez de Toledo en la América colonial: promotor legislativo de quien habla por «boca de». Apresentam-se os atributos que vai adquirindo o mediador linguístico e cultural, entre os anos 1570 e 1580, para conformar a identidade profissional da pessoa que traduz e interpreta no território do vice-reinado do Peru. O promotor desta figura é Francisco Álvarez de Toledo quem, ao promulgar as ordenanças sobre in- 
terpretação, reconhece a capacitação institucional das pessoas que traduziam e interpretavam durante a década mencionada. Tanto nos textos jurídicos e administrativos como nas Crónicas da conquista e da colonização aparecem locuções como «por boca de» ou «por voz de» que, ainda que não contenham a palavra intérprete, indicam a existência de um ato de mediação linguística e cultural, daí que o autor os denomine 'paraintérpretes'. Em geral, eram-lhes atribuídas outras profissões ou denominações como yanacona, pregoeiro, guia, defensor de pobres, porteiro, entre outros; pelo que as leis instauradas pelo vice-rei e sancionadas pela autoridade Real supõem o primeiro reconhecimento público da pessoa que traduz e interpreta na América.

M. a Ángeles Romasanta González parte da identidade individual, no seu capítulo «Aproximaciones a una traducción del espacio público», para analisar como se situa nele a identidade coletiva da cidade de Bilbao. Esta aparece descrita mediante a capacidade de empoderamento que possui cada grupo humano. Na realidade, paratraduz-se o espaço público da capital biscainha para assinalar as relações que existem entre o centro e a periferia. A autora manifesta que falta diálogo porque não se produz um reconhecimento do Outro, que aparece situado na periferia isolada e marginada dos bairros operários. Incorpora-se assim o pensamento liminar ao conceito de paratradução e põe-se em relevo as barreiras mentais e ideológicas que obstaculizam aos coletivos humanos que vivem no centro ou na periferia da cidade.

A ideia de limite é utilizada, também, por Emmanuel Claude Bourgoin Vergondy no capítulo «Odisea en el espacio público de la traducción e interpretación» para marcar as fronteiras legais, jurídicas e materiais a que estão sujeitos tanto os profissionais da TIMS (Tradução e Interpretação no Meio Social) como os migrantes que chegam à Galiza. Desta forma, observa como se desenvolvem os processos de tradução e interpretação nos âmbitos da justiça ou da polícia e deduz as carências na execução das escassas medidas que 
amparam tanto o exercício profissional como a pessoa que necessita apoio.

Um dos campos com maior expansão em Tradução e Interpretação é o da localização, concretamente a localização dos videojogos, como expõe Ramón Méndez González em «Los videojuegos como puente entre culturas: adaptación ideológica del producto a distintos mercados». Descrevem-se tanto a evolução como os diferentes tipos de localização, além da classificação dos seus agentes localizadores. Nem todos eles intervêm na produção de videojogos nem realizam estritamente trabalhos de tradução mas, de uma forma ou de outra, incidem no resultado da mesma, na medida em que colaboram na incorporação do bem cultural «videojogo» no mercado da sociedade, da língua e da cultura recetora.

Sobre uma série de postais, gravuras de imprensa e fotografias extraídos na sua maioria da coleção de investigação ICOTI (Iconografia Contemporânea da Tradução e Interpretação), Anxo Fernández Ocampo, em «La Zona. Límite, traducción y espacio social», destaca a natureza tradutora de determinados lugares. $\mathrm{O}$ espaço descrito pertence à denominada «Zona», situado na porta de Pantin de París durante o armistício da guerra franco-prussiana, entre 1870 y 1871 , onde uns tradutores se tinham instalado, à mercê do vento, nas imediações da porta para traduzir «o francês aos alemães e o alemão aos franceses». As imagens desse corpus constroem-se diretamente sobre os vínculos experimentados entre o espaço público e o seu ocupante, que serviu de cenário para a transformação das profissões e da divisão do trabalho, para novas formas de consumo e para o desenvolvimento de um regime de conhecimento visual em forma de ficção, literatura cinzenta, pintura ou fotografia.

O objetivo primordial de José Yuste Frías em «Por una comunicación transcultural en los servicios públicos de Traducción e Interpretación» é questionar-se sobre as noções de «intercultural» 
e «multicultural» no seu essencialismo, pôr em dúvida a ideia de que toda a «identidade cultural» tem a sua origem numa espécie de essência preexistente. Tanto o primeiro conceito como o segundo, territorializam qualquer produção verbal ou não verbal da «identidade cultural» ao reduzi-las a um determinado território, delimitado por fronteiras; com o qual, traduzir e interpretar ao sujeito migrante alofone que pretende beneficiar-se dos serviços públicos, só serve o fim político de determinar que território deve ocupar no espaço público do país que o acolhe. Propugna uma comunicação transcultural na TIMS (sigla da locução alcunhada pelo próprio autor) que permita pensar na interculturalidade e multiculturalidade sob o paradigma da tradução, onde a identidade é concebida por parte do tradutor intérprete como um devir em permanente construção.

O capítulo «El derecho de las personas acusadas y víctimas a entender y ser entendidas recogido en la legislación internacional y española», de Maribel del Pozo Triviño, recopila e examina diferentes textos legislativos sobre o direito das pessoas a entender e serem entendidas nos processos judiciais em três âmbitos de aplicação: o internacional, o europeu e o espanhol. A autora sublinha que só uns serviços de tradução e interpretação de qualidade cobrirão as necessidades das pessoas que não falam nem entendem o idioma do país onde se leva a cabo a tramitação de um processo.

Marta Araújo González, na contribuição «Mediación cultural y migración: estudio de un caso y contribuciones de la traducción y de la interpretación a la integración en la enseñanza pública», estende uma ponte entre três realidades: a educação pública, a diversidade cultural e a tradução e interpretação. Através de um estudo de caso e analisando o marco legal que apoia os alunos procedentes do estrangeiro, a autora estabelece de que maneira os professores deveriam afrontar as necessidades de integração das pessoas alofones no sistema educativo galego. 
No capítulo «Códigos de conducta y calidad en traducción», de Ana Luna Alonso, aborda-se a questão da conciliação entre deontologia e carácter de serviço ao público das pessoas que traduzem e interpretam. Reveem-se os principais convénios e protocolos que promovem as instituições, tanto do âmbito internacional como estatal, e os estatutos de algumas associações profissionais. A professora Luna esmiúça este corpus para concluir que num mercado globalizado com as suas respetivas leis, a crise económica e o poder de grandes multinacionais provedoras de serviços linguísticos, estão por trás da baixa qualidade dos trabalhos de tradução.

Áurea Fernández Rodríguez propõe a análise de um corpus de textos especializados originais em francês que tratam da reforma no capítulo intitulado «Vida laboral en Francia y jubilación de residentes extranjeros. Estudio comparativo como ayuda a la traducción». Cabe destacar o ponto de vista didático que adota ao realizar uma análise concisa da metodologia de tradução que se deveria utilizar na hora de fazer frente a este tipo de textos. A série de referências bibliográficas que se oferece é de grande ajuda tanto para os alunos como para os professores da disciplina de tradução de textos especializados na combinação linguística francês-espanhol/galego.

O fecho desta publicação fica a cargo de Xoán Montero Domínguez com «La traducción audiovisual en las lenguas emergentes. El caso del asturiano en la televisión pública de Asturias». O autor analisa o papel que teve a televisão autonómica a partir do ano 2008 no processo de normalização linguística na língua asturiana. Também destaca a função preponderante que tiveram os meios de comunicação como difusores de modelos linguísticos que marcam o caminho a seguir pelos falantes deste idioma minoritário. Finalmente, defende a criação de uma indústria de dobragem em asturiano, permitindo assim a progressiva criação de uma rede de agentes normalizadores da língua. 
Definitivamente, Traducir e interpretar lo público abre novos horizontes para a investigação com a publicação de um material pouco acessível e inédito. Esta interessante contribuição para os Estudos de Tradução e Interpretação é, sem dúvida, uma leitura recomendável tanto para os alunos como para os professores desta disciplina.

Recebido em: 27/03/2017

Aceito em: 15/06/2017

Publicado em setembro de 2017 